\title{
Derivas urbanas: la ciudad extrañada
}

\author{
Roger Paez i Blanch*
}

Resumen / Abstract pág 51 | Bibliografía pág 53

"La elaboración de mapas psicogeográficos, (...) puede contribuir a clarificar ciertos desplazamientos de carácter no precisamente gratuito, pero sí absolutamente 'insumiso' a las influencias habituales." ${ }^{1}$

Este artículo presenta una serie de cartografías urbanas que documentan la ciudad en función de una acción concreta: una deriva. Los mapas resultantes ponen de manifiesto una relación intensa con la ciudad a partir de una vivencia concreta donde la ciudad es tratada simultáneamente como material y como soporte de investigación.

El objetivo implícito de todos estos experimentos es mostrar la reorientación radical que sufre la ciudad cuando es apelada desde un interés o una voluntad concretas.

Mostrar la plasticidad del fenómeno urbano a través de mapas que tensionen las imágenes que tenemos de la ciudad tiene un doble sentido. En primer lugar multiplicar las perspectivas a través de las cuales percibimos y construimos mentalmente la ciudad: un mundo plural requiere imaginerías plurales. En segundo lugar, abrir nuevos caminos a la transformación de la ciudad, tanto a nivel físico como a nivel de uso: nuevas narrativas urbanas promueven nuevas prácticas urbanas.

\section{Modos de deriva}

El concepto de deriva, acuñado por Guy Debord en los años cincuenta, ha superado su marco de referencia original y se ha convertido en un concepto clave para entender múltiples prácticas urbanas, tanto anteriores como posteriores a la su conceptualización inicial.

Si la entendemos de manera amplia, ${ }^{2}$ la deriva es una práctica de conocimiento e interacción con la ciudad basada en recorrerla siguiendo lógicas no-habituales, ya sean azarosas o construidas.

La historia de la deriva es larga y ya ha sido estudiada ampliamente. ${ }^{3}$ Sin entrar en disquisiciones de gran calado, vale la pena recordar que la práctica de la deriva proviene de la flânerie, un tipo de pasear ocioso, simultáneamente distraído e inquisitivo, que aparece con la modernidad. A mediados del siglo XIX, a causa de la expansión de las grandes ciudades de la primera industrialización, la ciudad se entiende, por primera vez en la historia, como un mundo donde es posible perderse. La ciudad, transformada en autentica naturaleza urbana ${ }^{4}$, aparece como un lugar de descubierta. Es en este marco de simultánea fascinación e incomprensión de la urbe industrial donde los flâneurs inician las primeras proto-derivas.

A pesar de todo, no es hasta los años veinte que recorrer la ciudad aparece como una actividad obstructiva-creativa consciente y voluntaria. ${ }^{5}$ En el período de Entreguerras y muy especialmente después de la Segunda Guerra Mundial, la deriva se entiende como un modo de desobjetivización de una ciudad que se ha convertido en un campo totalmente dominado por el capital. La deriva es una de las técnicas que se usan para buscar agujeros en una realidad monolítica caracterizada por la alienación, la trivialidad y el ennui., 7

Dentro de la historia de la deriva se pueden distinguir dos grandes momentos, separados por la experiencia de la Internacional Situacionista.

\author{
Palabras clave \\ deriva \\ ciudad \\ mapa \\ cartografía operativa \\ desorientación \\ situacionista \\ patafísica \\ psicogeografía
}

\footnotetext{
1 "La fabrication de cartes psychogéographiques (...) peuvent contribuer à éclairer certains déplacements d'un caractère non certes de gratuité, mais de parfaite 'insoumission' aux sollicitations habituelles." Debord, Guy; "Introduction à une Critique de la Géographie Urbaine", Les Lèvres Nues, n6, Septiembre, 1955. (Trad. de Lurdes Martinez)

2 Es decir, no limitada a su conceptualización debordiana. El 1952 Debord plantea la conceptualización inicial de la deriva como "una aprehensión no-óptica del espacio urbano". Cuatro años más tarde, Debord propone la conceptualización clásica de la deriva situacionista: "técnica de transición fugaz a través de ambientes cambiantes". Cuando hablamos de deriva en su acepción amplia, incluimos a demás de la deriva letrista-situacionista propiamente dicha las experiencias asimilables anteriores, como por ejemplo las flâneries del XIX, las vistas Dadá, las excursiones y deambulaciones surrealistas, asi como las experiencias posteriores relacionadas con el desplazamiento como método de conocimiento y producción artística: desde los happenings de los sesenta a los new spatial media del 2000, pasando por las exploraciones del land-art, el arte conceptual, el activist mapping, o la transurbancia.

${ }^{3}$ Ver, por ejemplo: Hollevoet, Christel / Jones, Karen / Timothy Nye; The Power of the City / The City of Power, The Whitney Museum of American Art, New York, 1992. Sadler, Simon; The Situationist City, The MIT Press, Cambridge, 1998. Careri, Francesco; Walkscapes, Gustavo Gili, Barcelona, 2008

4 "El París de Benjamin, efectivamente, se asemeja mucho a una naturaleza virgen y sin nombre, todavía no reducida a categorias epistemológicas".

Llovet, Jordi; "Benjamin i Paris", Walter Benjamin i l'esperit de la modernitat, Jordi Llovet, Barcanova, Barcelona, 1993, pág 283. (Trad. del autor) El propio Walter Benjamin, en el texto "El Paris del Segundo Imperio en Baudelaire", escrito originalmente el año 1937-38, dice que Baudelaire "iba a hacer botánica en el asfalto".

${ }^{5}$ El 14 de abril de 1921 el grupo DADA formado por Aragon, Arp, Breton, Buffet, Éluard, Fraenkel, Hussar, Picabia, Ribemont-Dessaignes, Soupault, y Tzara, organiza la "1ère. Visite Saint Julien le Pauvre". El mayo de 1924, los surrealistas Aragon, Breton, Morise y Vitrac hacen una caminata aleatoria de Blois a Romorantin. Estas experiencias son recogidas en la literatura de algunos de sus participantes (Aragon; Le Paysan de Paris, 1926; Breton; Nadja, 1928)

6 "En mayo de 1924, Aragon, Breton, Morise y Vitrac determinaron al azar, sobre un mapa de carreteras, el recorrido a efectuar: de Blois a Romorantin. La inutilidad total de este itinerario creó, para los caminantes, las condiciones de disponibilidad indispensables para captar lo sureal en lo real, lo maravilloso en lo ordinario, lo fantástico en lo trivial"

Paquot, Thierry; Des corps urbains: Sensibilités entre béton et bitume, Autrement, Paris, 2006, pág 88.

7 "La crisis del urbanismo se agrava. (...) Un ambiente mortecino y estéril es el resultado en nuestro entorno. (..) y toda preocupación lúdica está ausente. Ante la necesidad de construir rápidamente ciudades enteras, nos disponemos a construir cementerios de hormigón armado, en los que grandes masas de la población están condenadas a morirse de aburrimiento. (...) Nosotros reivindicamos la aventura." Constant; "Une autre ville pour une autre vie", Internationale Situationniste n³, Diciembre, 1959.
} 


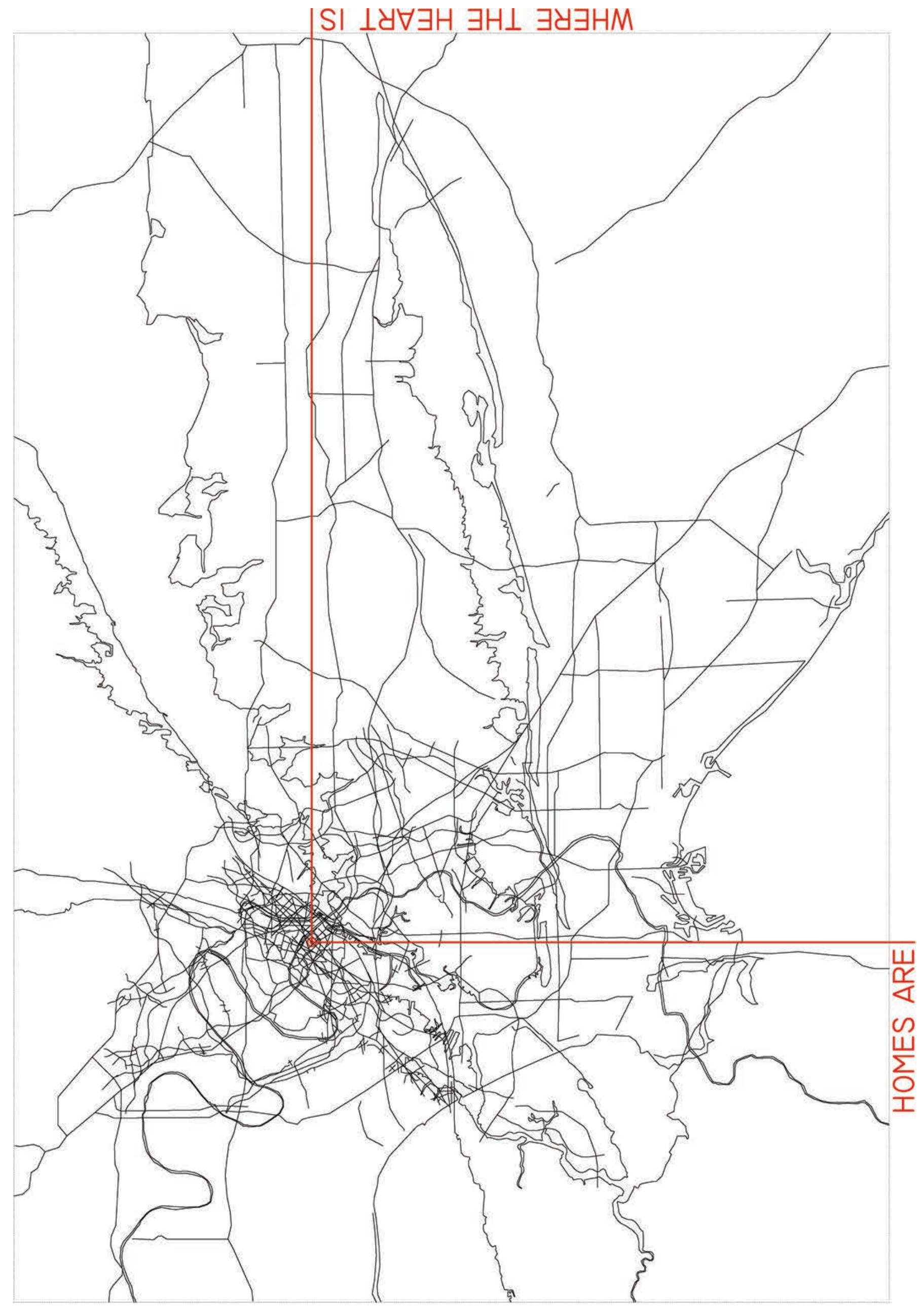




\section{JOURS À PARIS}

En un primer momento, desde los flâneurs hasta los surrealistas, la deriva es un viaje sin finalidad concreta empujado por la voluntad de ver, de descubrir aspectos desconocidos u ocultos de la ciudad. El motor es el azar y la técnica es la observación alterada.

Después de la intensa experiencia situacionista, la deriva se convierte sobretodo en una construcción, donde las hipótesis y las instrucciones de la acción se plantean con el objetivo de generar fricción con la realidad urbana en la cual se inscriben. Más allá de su voluntad de poner de manifiesto realidades alternativas, la deriva a partir de los situacionistas se plantea en términos de una realidad demasiado estrecha.

La Internacional Situacionista efectúa un viraje fundamental en la deriva, pasando del paradigma de la observación al de la transformación. ${ }^{8}$

\section{Extrañamiento y desorientación}

La deriva es una de las técnicas de desorientación por excelencia, en el sentido que provoca un extrañamiento respecto al entorno urbano cotidiano. A través de la deriva, se provoca un cambio de mirada, una percepción renovada de la ciudad que normalmente percibimos desde la rutina y a través de una recepción distraída. ${ }^{9}$ La deriva busca articular la percepción de la ciudad de manera que "nadie (caiga) en la trampa del hábito". ${ }^{10}$

En su texto "El principio de la desorientación" Constant apunta muy claramente a la desorientación como mecanismo desobjetivizador de la ciudad y dispositivo necesario para la construcción de una vida libre y creativa. ${ }^{11}$

Integrándose dentro de la tradición crítica con los efectos alienadores de la modernidad industrial, Constant opone al espacio estático de la sociedad utilitarista el espacio dinámico al cual conducirá una sociedad lúdica. En la sociedad utilitarista la construcción del espacio se basa en el principio de la orientación, plegando la totalidad del espacio social al espacio del capital. El espacio del capital se mide desde el ángulo de la utilidad, la eficiencia y la producción de plusvalía a partir del trabajo.

La sociedad lúdica, en cambio, conduciría inevitablemente a una dinamización del espacio, puesto que este dejaría de entenderse bajo la óptica homogeneizadora del trabajo y pasaría a activarse desde la lógica transformadora del Homo ludens. ${ }^{12}$ El Homo ludens actúa sobre su entorno y lo dinamiza, más que un entorno de trabajo el espacio se convierte en terreno y a su vez "objeto de juego, aventura y exploración". ${ }^{13}$

La desorientación dinamiza el uso del tiempo y el espacio favoreciendo una forma de vida lúdica y creativa.

El espacio social de la sociedad lúdica tiene que ser, según Constant, laberíntico y al mismo tiempo continuamente modificable: "ya no se tratará de desviarse en el sentido de 'perderse' sino en el sentido más positivo de 'encontrar caminos desconocidos' ".14 El espacio está sometido a un proceso continuo de creación y destrucción dirigido por la apropiación lúdica y creativa orientada a la ampliación del campo vital: "La creación y recreación continuas de modos de comportamiento requieren una construcción y reconstrucción ininterrumpida de su escenografía. En eso consiste el urbanismo unitario."15

La deriva, a partir de su capacidad de promover el extrañamiento, incrementa las filas de los mecanismos que obstruyen la expectativa predeterminada, que devuelven la experiencia al campo del descubrimiento, la sorpresa y la vivencia, ampliando así el campo de la realidad: élargir la vie.

\section{Vivencia y colapso lugar-acción}

En la vivencia o experiencia concreta se construye el lugar ligado indisolublemente a la acción. La vivencia efectúa un colapso entre el marco espacial y la acción que este acoge, de tal manera que al límite se llega a una supresión momentánea de la distinción entre sujeto y objeto.

Ernst Mach expresa este colapso de la siguiente manera: "un día despejado de verano al aire libre se me apareció el mundo juntamente con mi Yo como una masa coherente de sensaciones, solo que en el Yo era mucho más coherente. (...) ese momento resultó decisivo para toda mi visión." ${ }^{16}$ La vivencia posee una calidad epifánica que puede llegar a confundir

8 “Lanzando el famoso slogan de Mayo del 68 'TOMA TUS DESEOS POR REALIDAD', la I.S. defendió una consciencia aumentada, una acción directa, y una intervención sistemática en la vida real, Debord insistió en que "la deriva y la situación van más allá de los 'paseos idiotas' de los surrealistas."

Hollevoet, Christel; "Wandering in the City", en Hollevoet, Christel / Jones, Karen / Timothy Nye; The Power of the City / The City of Power, The Whitney Museum of American Art, New York, 1992, pág 33.

${ }^{9}$ Respecto al concepto de recepción en la distracción, ver Benjamin, Walter; La obra de arte en la época de su reproductibilidad técnica (1935), Taurus, Madrid, 1973

10 "Los sectores cambian constantemente de forma y de atmosfera de acuerdo con las actividades que alli ocurren. Nadie puede volver a lo que había antes, redescubrir un lugar tal y como uno lo dejó, reencontrando la imagen que uno retuvo en la memoria. Ahora nadie cae en la trampa del hábito" Constant; "New Babylon, Outline of a Culture", New Babylon exhibition catalogue, Haags Gemeetenmuseum, The Hague, 1974, pág 167. 11 Constant; "El Principi de la Desorientació", Situacionistes. Art, Política, Urbanisme, Eds. Libero Andreotti / Xavier Costa, Actar, Barcelona, 1996, pág 86-87. En este texto Constant re-elabora la noción de desorientación planteada en sus propios textos de los años 1950s (ver por ejemplo Constant; "Une autre ville pour une autre vie", Internationale Situationniste n ${ }^{3} 3$, Diciembre, 1959. Constant; "New Babylon, Outline of a Culture", New Babylon exhibition catalogue, Haags Gemeetenmuseum, The Hague, 1974). Constant, de hecho, profundiza en el tema planteado por el letrista Ivan Chtcheglov (alias Gilles Ivain), Chtcheglov, Ivan; "Formulaire pour un urbanisme nouveau" escrito el año 1953. Una versión reducida se publicó en Internationale Situationniste $n^{\circ} 1$, París, Junio, 1958.

12 Johan Huizinga publica el año 1938 el libro Homo ludens, que se convierte en una gran influencia a partir de las traducciones en lengua alemana (1944), inglesa (1949) y francesa (1951).

13 Constant, 1996, pág 86.

14 Constant, 1996, pág 87.

15 Constant, 1996, pág 87.

${ }^{16}$ Ernst Mach (1922) citado por Alois M. Haas; Viento de lo Absoluto: ¿Existe una sabiduría mística de la posmodernidad?, Siruela, Madrid, 2009 , pág 63. Después de la cita de Mach, el texto de Haas continua asi: “Expresado con otras palabras: la mémoire involontaire de Proust, las 'epifanias' en 
BCN RDMP = A PERIPATHETIC INE-DAY CLASS CDNSISTING DF A 25.871 M LING WALK INVDLVING BREAKWATER-TRESPASSING, SAND-WADING, RUNNING, BACKWARD-STRDLING, LANDFILL-LOITERING, CITY-CRDSSING AND A FINAL STRETCH DF 2404 M WITH A GRADE DF 212 M CARRYING TWI BRICKS EACH

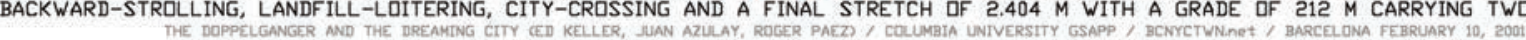

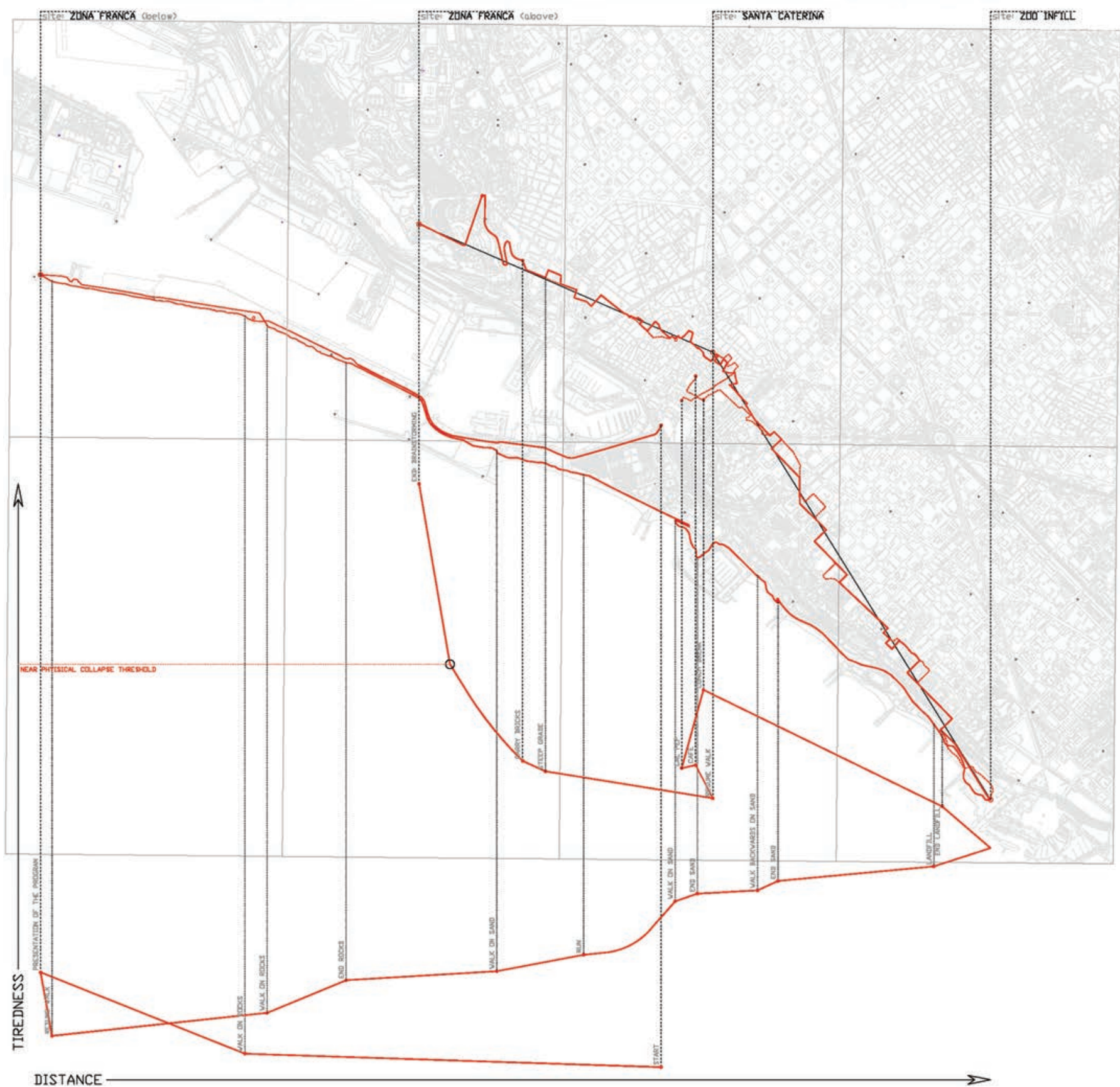

[3] BCN romp. Roger Paez i Blanch, 2001. Comprensión de la ciudad a través de una experiencia extrema que tiene el cuerpo como limite. el aquí (lugar) con el ahora (momento). A través de la interpretación existencialista del concepto hic et nunc, se traza una trabazón indisoluble entre conocimiento y subjetividad. ${ }^{17} \mathrm{El}$ conocimiento generado desde una subjetividad concreta no es transferible intersubjetivamente en tanto que conocimiento vivido, pero sí que puede serlo en tanto que manera de conocer. En otras palabras, no se pueden compartir radicalmente las visiones pero sí las maneras de ver.

En este sentido el mapa de la deriva, toma un carácter de filtro intersubjetivo, mediante el cual la experiencia subjetiva se construye como herramienta de ampliación (de la percepción) del mundo.

En el marco de la arquitectura y las disciplinas proyectuales, el objetivo de las cuales es la transformación de un espacio físico que siempre es social, la idea de filtro intersubjetivo toma una fuerza notable, ya que sitúa el proyecto tan alejado de una mera respuesta tecnocrática como de una pura expresión de deseo subjetivo.

El mapa de la deriva, y en general toda cartografía operativa, ${ }^{18}$ utilizada como sistema de mediación intersubjetiva, se convierte en un potente mecanismo problematizador. Más allá de

el sentido de Joyce, los moments of being en el sentido de Virginia Woolf, los 'instantes' de Thomas Mann o el 'ensayo sobre un día logrado' de Handke propician un acceso a estadios de percepción cuyo sentido permanecía hasta entonces en lo extralingüistico e inexpresable."

17 "Yo soy el hic et nunc (ahora y aqui) sobre el cual descansa toda la realidad objetiva. Y por más desnudo que sea, mi conocimiento queda siempre ligado a mi punto de vista. Por mucho que quiera dejar de ser el centro jamás puedo ponerme en el punto de vista de Sirius, que sería el único y verdadero." (Trad. del autor). Karl Jaspers, según Ricœur, Paul / Dufrenne, Mikel; Karl Jaspers et la philosophie de l'existence (1947), Seuil, Paris, 2000

18 Para una introducción al concepto de cartografía operativa, ver Paez, Roger; "Cartografías Operativas y Mapas de Comportamiento", Querido Público: El espectador ante la participación: jugadores, usuarios, prosumers y fans, Roger Bernat / Ignasi Duarte, CENDEAC, Murcia, 2009 pág 173-199. 
su valor de documento íntimo, el mapa permite articular una posición subjetiva en fricción con la realidad objetiva como pregunta o enunciado -no conformándose con la mera resolución acrítica de problemas cuyos parámetros ya están dados por el status quo.

\section{Nueve mapas nuevos (derivas urbanas)}

Si la teoría entorno de la deriva es amplia y fecunda, no lo es tanto la producción de mapas ligados a ella. A continuación presentamos nueve mapas de derivas urbanas, realizados por el autor entre 2001 y 2011. Estos mapas se proponen como instrumentos de investigación que buscan profundizar en la riqueza del fenómeno urbano, aproximándose a la realidad de la ciudad desde ángulos distintos de los habituales, ya que éstos pierden potencia crítica al teñirse por la costumbre y la rutina. En origen estos mapas aparecieron como un ejercicio privado, fruto de una necesidad íntima de dibujar aspectos de la ciudad sistemáticamente obviados que, a pesar de todo, afectan de manera muy importante a nuestras vidas. Como ya avanzábamos al principio, mostrar la plasticidad del fenómeno urbano a través de estos mapas tiene un sentido simultáneamente hermenéutico y transformador. Ampliar la comprensión de la ciudad amplía las vías para transformarla: nuevas narrativas urbanas promueven nuevas prácticas urbanas.

I. Homes are where the heart is [1]. Superposición de los mapas de Barcelona, París, Nueva York y Los Angeles, a la misma escala y con la misma orientación, centrados respecto el punto de residencia del autor. El hogar, uno y múltiple, deviene el eje entorno del cual se organiza el mundo circundante -un axis mundi transportable.

II. 5 jours à Paris [2]. Durante cinco días de vacaciones en París, las reglas del juego se limitan a ir por todas partes a pie. Una simple decisión instrumental afecta radicalmente a la percepción de la ciudad y las actividades que en ella se desarrollan. La extensión y la fisicidad de la ciudad se ponen de relieve. Las relaciones de contigüidad se evidencian y los movimientos persiguen y descubren viejos canales: vaguadas, caminos suburbanos, rutas romanas. En un gesto de restricción voluntaria, el mapa reduce la experiencia de la ciudad a la distancia caminada cada día. Cinco stoppages étalon.

[4] Behavioural symmetry of Porto. Roger Paez i Blanch, 2011.

Buscando una manera de poner de manifiesto el orden topográfico de la ciudad de Oporto, se plantea bajar desde el punto más alto de la ciudad hasta el río siguiendo la máxima pendiente.

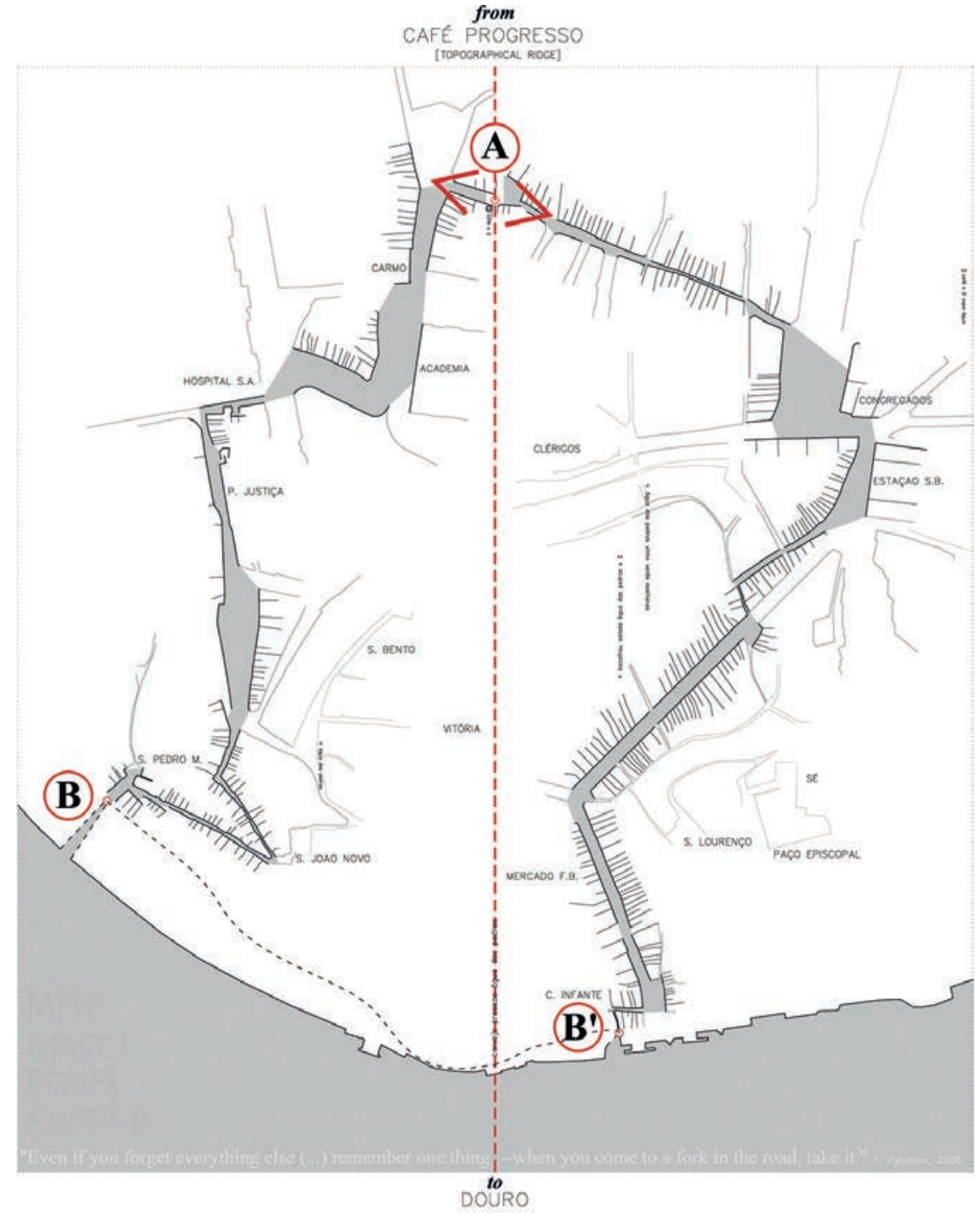

BEHAVIOURAL SYMMETRY OF PORTO 
III. BCN romp [3]. Clase peripatética realizada en el marco de una colaboración académica con la Universidad de Columbia (Nueva York). Para introducir la realidad urbana de Barcelona a una serie de estudiantes americanos se decide usar el cuerpo como instrumento de medida. Evitando aproximaciones librescas, para conocer el sitio donde tienen que trabajar, los estudiantes extranjeros son sometidos a una agotadora clase consistente en caminar casi $26 \mathrm{~km}$. La ruta pasa por escollos y playas, algunos tramos se hacen corriendo y otros caminando de espaldas, y los últimos 2,5 km se sube a la montaña de Montjuïc acarreando dos ladrillos por persona. El cansancio se convierte en protagonista. La ciudad se percibe a través de un filtro corporal que bloquea aproximaciones excesivamente distanciadas y analíticas, forzando una comprensión de la ciudad indisolublemente ligada a una experiencia extrema que tiene el cuerpo como límite.

IV. Behavioural symmetry of Porto [4]. Hay ciudades en las que siguiendo el mapa uno se pierde, ciudades donde las lógicas de su forma están dictadas por parámetros distintos a la organización en planta. Oporto, con su orografía compleja, es una de ellas. Buscando una manera de poner de manifiesto el orden topográfico de la ciudad de Oporto, se plantea bajar desde el punto más alto de la ciudad hasta el río siguiendo la máxima pendiente. Como el punto más alto es una línea de cresta perpendicular al río, es necesario realizar el trayecto descendiente dos veces. Los dos recorridos descendientes, que a modo de ríos secos revelan lógicas internas de la estructura urbana, generan una simetría que no es formal sino performativa.

V. Da San Luca a Santa Caterina senza carta [5]. Desde que la góndola no es el modo de transporte dominante, Venecia se ha convertido en laberíntica. Su peculiar morfología responde a lógicas de navegación, y recorrer la ciudad a pie es hacerlo a contrapelo. Esta deriva parte de la fascinación por la facilidad de desorientarse en Venecia. Un día, paseando sin rumbo concreto, el azar nos lleva de la iglesia de Santa Caterina (Cannareggio) a la iglesia de San Luca (San Marco). La mañana siguiente, sin mapa, se intenta rehacer el camino inverso. El resultado muestra tres maneras de ir de un sitio a otro: el recorrido azaroso inicial, el recorrido

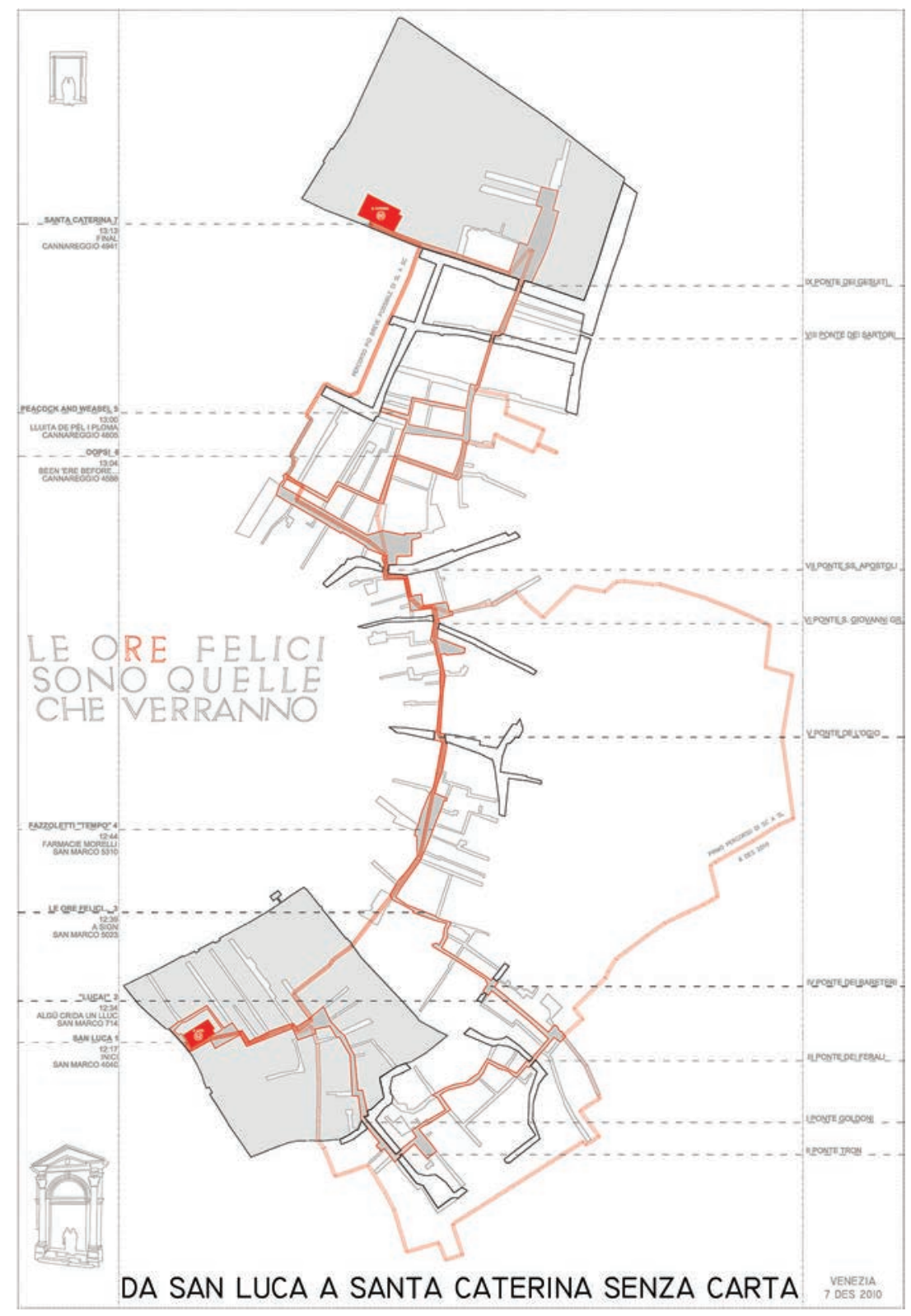



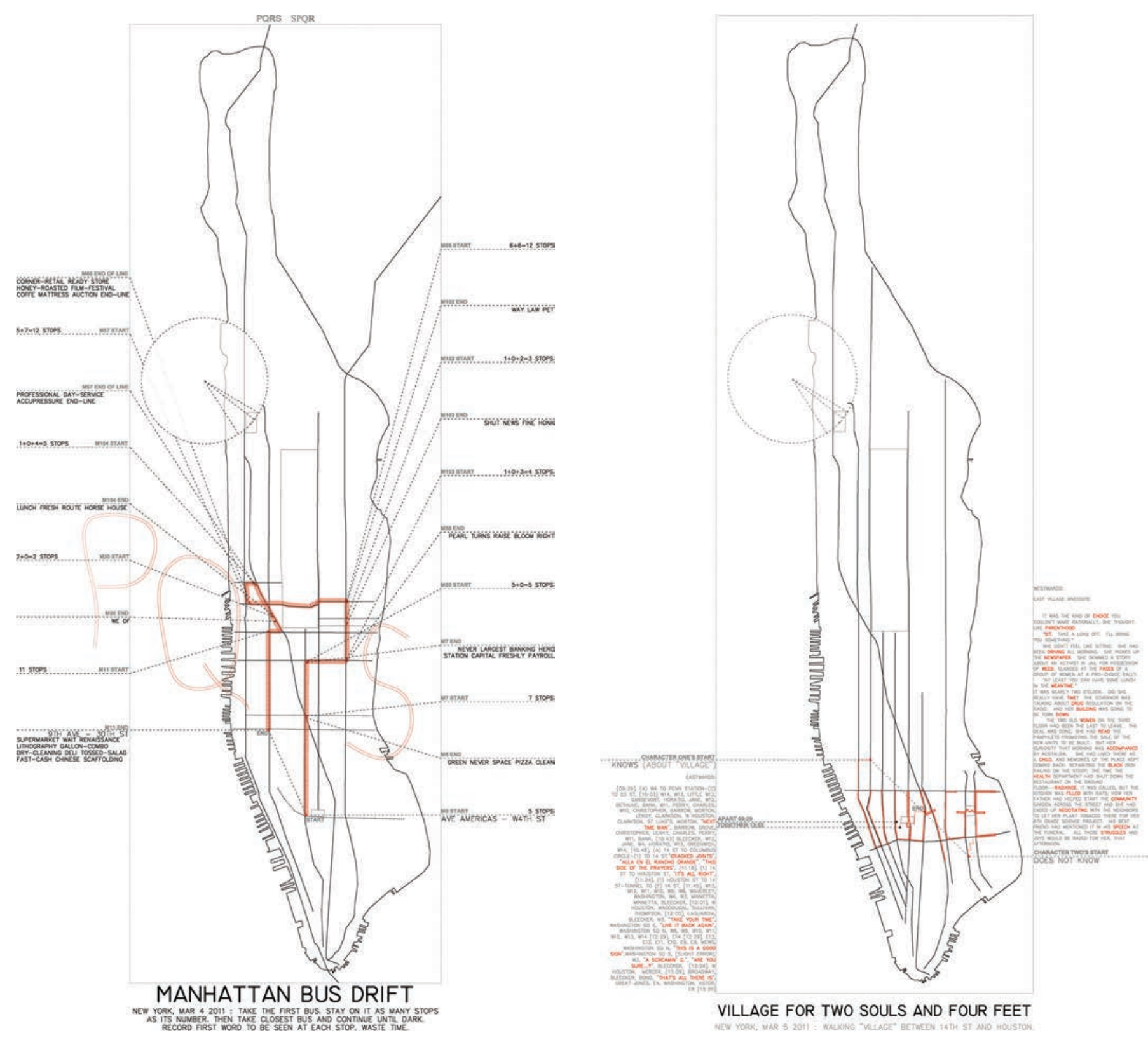

[6] Manhattan bus drift.

Roger Paez i Blanch, 2011

El recorrido marcado es el resultado de un juego: quedarse en el autobús tantas paradas como indique su número de línea, bajar y tomar el prime autobús que pase por la primera parada que uno encuentre y repetir la operación hasta que anochezca.

[7] Village for two souls and four feet. Roger Paez i Blanch y Angela Kay Bunning, 2011 En esta deriva realizada a cuatro pies, se escribio el nombre de VILLAGE en toda la extensión de este barrio neoyorquino. sin mapa, y el recorrido más directo posible trazado sobre el mapa. Las diferencias entre estos tres caminos ponen en relieve la falta de coincidencia entre la imagen mental y el espacio real de la ciudad.

VI. Manhattan bus drift [6]. A principios de marzo hace frío en Nueva York, especialmente si toda tu ropa se encuentra en una maleta que se ha extraviado en JFK. Perder el tiempo es una tarea apasionante. Una manera barata de pasar unas horas en Manhattan es tomando el autobús climatizado. Para hacer la experiencia más interesante se plantea un juego: quedarse en el autobús tantas paradas como indique su número de línea, luego bajar y tomar el primer autobús que pase por la primera parada que uno encuentre y repetir la operación hasta que anochezca. Días después, al transcribir la ruta resultante sobre el mapa aparece claramente la letra "R". Como ya sabían Major Brown (Chesterton), Lönnrot (Borges), o Stillman (Auster), la ciudad habla a través de nuestras acciones. A pesar que no seamos conscientes de ello.

VII. Village for two souls and four feet [7]. La mirada sobre la ciudad depende mucho de las expectativas que tengamos. En esta deriva realizada a cuatro pies, se escribió el nombre de VILLAGE en toda la extensión de este barrio neoyorquino. Uno de los participantes era consciente de la acción, mientras que el otro simplemente seguía instrucciones ciegamente. La épica de la escritura-acción se hizo presente en el primer caso, por ejemplo en el reconocimiento de la inflexión de la V en el Bleecker Playground, que articula Hudson St y 8th Ave: la gran V aparece como una realidad manifiesta y clara en la forma de la ciudad. En el segundo caso, el desconocimiento del objetivo de la acción llevó al participante a estructurar su experiencia a través de una narración de matriz oulipiana. Desde la consciencia y la inconsciencia, en un acto fundacional retroactivo, se dibuja el nombre sobre toda la extensión de la cosa.

VIII. Un passo d'angelo [8]. Los lugares son también sus historias. En Roma la figura del ángel es omnipresente, y así lo reconoció Enric Miralles en su propuesta para el Borghetto Flaminio 


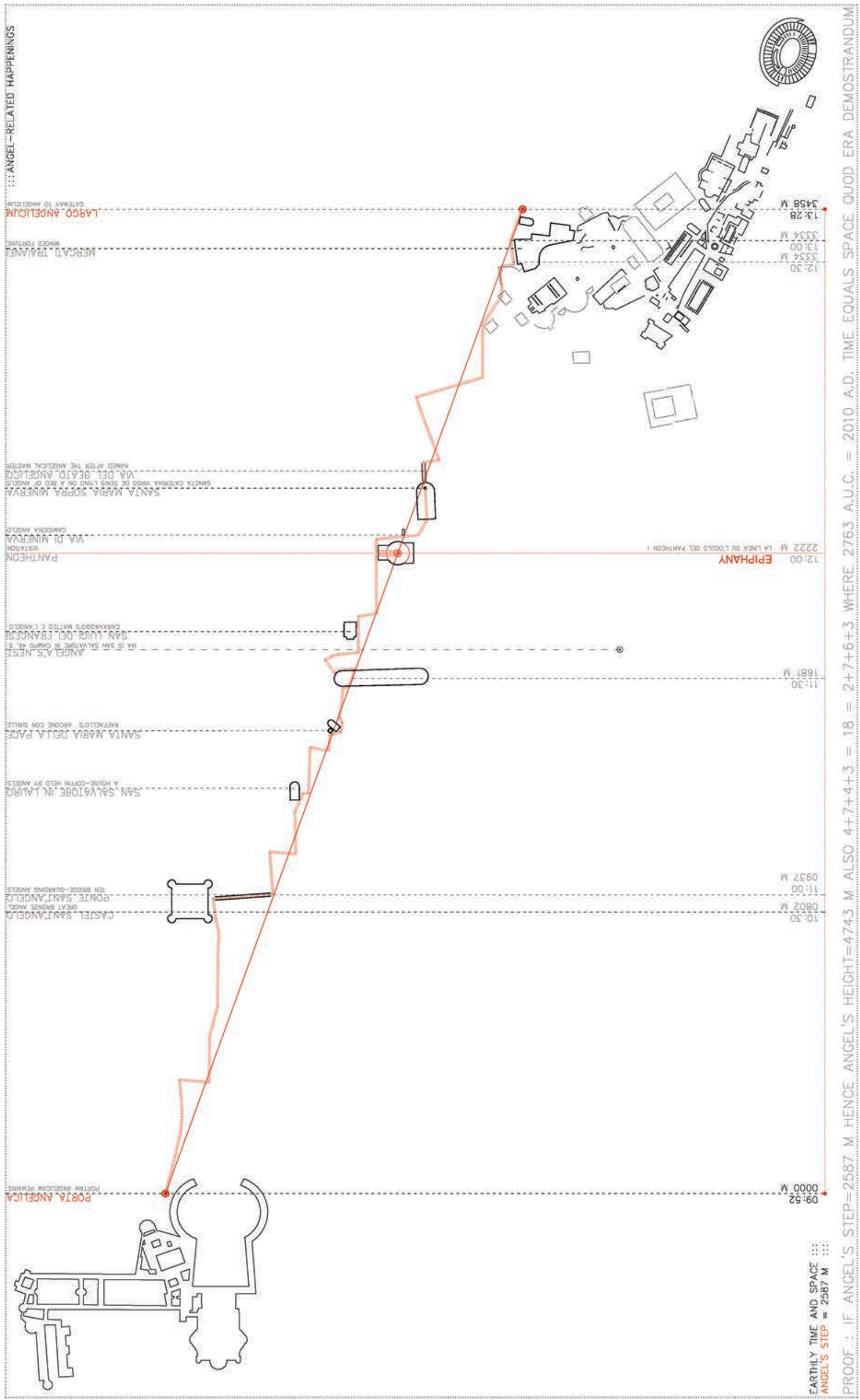




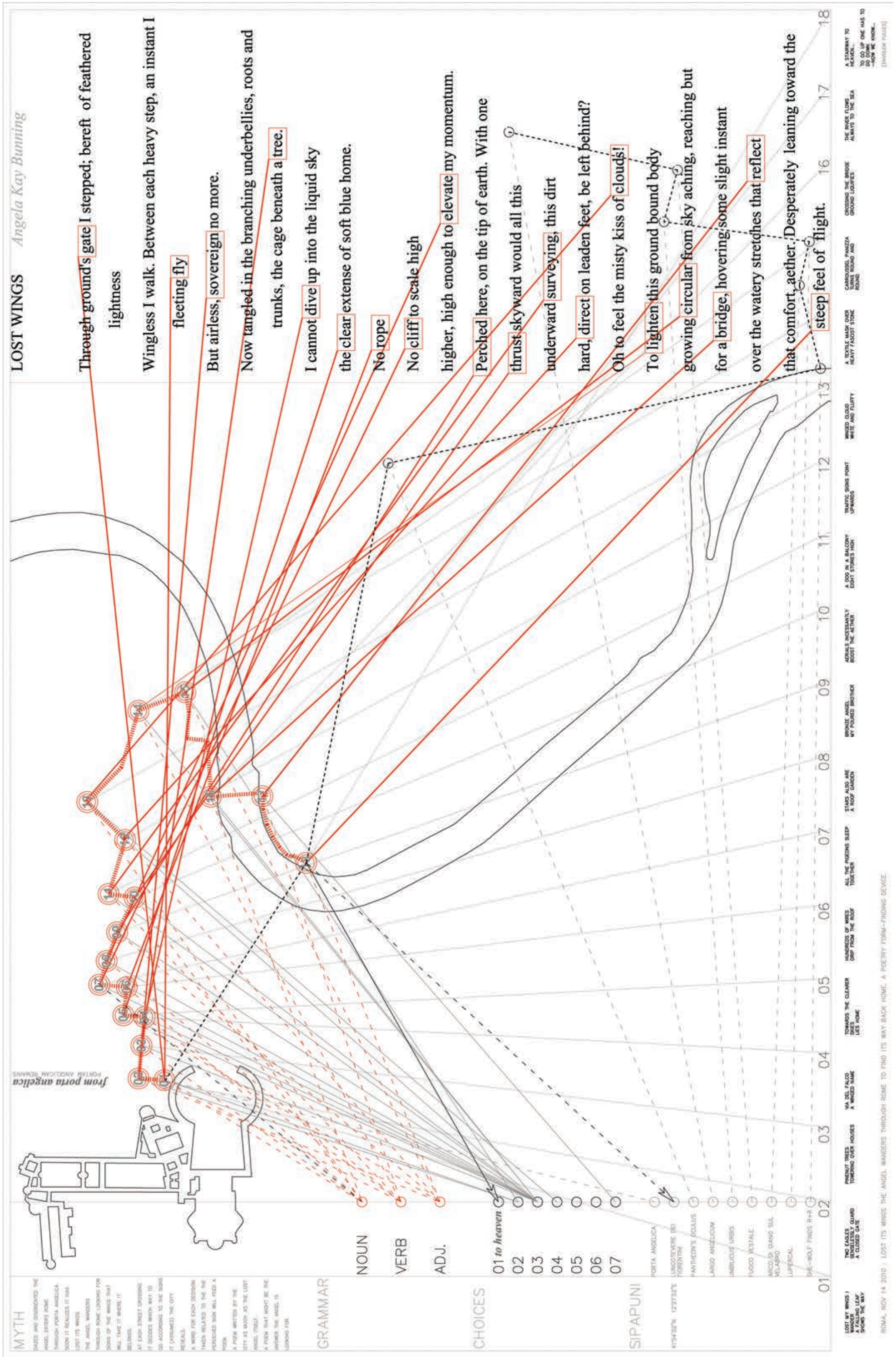


del año 1995. Siguiendo aquella Passeggiata dell'Angelo, nos proponemos caminar un solo paso de ángel, definido por la línea recta que une los dos únicos topónimos angélicos de la Roma aureliana: la Porta Angelica del Vaticano y el Largo Angelicum al Viminale. La deriva sigue la ruta más próxima posible a la línea recta entre estos dos puntos, y registra todas las apariciones angélicas a lo largo del recorrido, desde la iconografía a la rotulación comercial. Que la línea recta pasara exactamente por el óculo del Pantheon es objeto, todavía hoy, de escalofríos epifánicos.

IX. Lost wings [9]. La segunda deriva angélica en Roma parte de usar la ciudad como material poético en un sentido radicalmente material. A partir de un nódulo argumental básico -en Roma un ángel busca sus alas para poder volver a casa- se plantea la deriva como una máquina de interpelar la ciudad para extraer palabras que permitan construir un poema que desarrolle el argumento básico. Lost Wings es un ensayo de construcción mítica de un lugar. También es un intento de contribuir a una comprensión más rica del lugar físico $41^{\circ} 54^{\prime} 02^{\prime \prime} \mathrm{N} 12^{\circ} 27^{\prime} 52^{\prime \prime} \mathrm{E}$. El mapa pone de manifiesto la movilización de un espacio físico (Roma), a través de una acción (deriva urbana) que responde a un marco narrativo (el ángel que busca sus alas), para condensar estos múltiples niveles del lugar en un poema, la forma del cual queda indisociablemente ligada a la experiencia concreta de construcción del lugar. El mapa resultante, al mostrar los engranajes de este proceso, revela, sobretodo, la ligazón entre lugar físico y lugar narrativo, entre topos y logos, poniendo de manifiesto el carácter construido de todo lugar.

En cada uno de los casos anteriores, el mapa de la deriva puede tomar diversas posiciones relativas respecto la acción de la deriva: un mapa tanto puede ponerse delante como detrás de la realidad respecto a la cual se genera ${ }^{19}$. Es una herramienta doble hilo: a la vez hermenéutica y proyectiva. El mapa puede documentar una acción llevada a cabo en la ciudad [4, 5, 6]. El mapa puede orientar una acción en la ciudad $[3,8]$. El valor del mapa cambia en ambos casos. En el primer caso muestra un lugar-acción, en el segundo emplaza a una acción que encuentra su fuga en otros niveles, por ejemplo en la percepción ultra-intencionada de la ciudad o en la fricción entre instrucción (narrativa) y realidad (ciudad). Otros casos son más complejos, y el rol del mapa es más problemático y matizado [7, 9].

\section{Objetividad cartográfica y 'patafísica}

Utilizar mapas para producir y documentar derivas no es inmediato; hay otros formatos válidos como la fotografía o la narración. El aura de objetividad de la cartografía, sin embargo, resalta el ethos simultáneamente crítico y juguetón de la deriva. El mapa proviene de una genealogía militar que le otorga una imagen de objetividad legitimada a lo largo del tiempo. La historia dominante del mapa, ha sido y en cierta medida todavía es una historia de documento como mínimo territorializador, y muy a menudo conquistador o colonial. Su objetivo habitual es definir sin dudas ni matices por un lado fronteras y territorios (mapa político); y por otro lado ríos, mares, montañas y llanuras (mapa físico).

La 'patafísica, que Jarry describe como "la ciencia de las soluciones imaginarias" ${ }^{20}$, provoca una inversión apasionante en el modelo científico, ya que utiliza medios científicos para tratar temas radicalmente ajenos a su campo, con el objetivo de utilizar el modo de expresión dominante y con legitimidad social (la ciencia) para hacer aflorar cuestiones fundamentales que este modo de expresión excluye: "En aquella edad, que conservó toda su vida, el doctor Faustroll era un hombre de talla media, es decir, para ser exactamente verídico, de $\left(8 \times 10^{10}+\right.$ $10^{9}+4 \times 10^{8}+5 \times 10^{6}$ ) diámetros de átomos". ${ }^{21}$

Los mapas de derivas presentados son mapas 'patafísicos. Utilizados como mecanismo multiplicador de perspectivas, el mapa aparece como un documento de enorme potencia transformadora.

* Roger Paez i Blanch es arquitecto (ETSAB) y M. S. en Diseño Arquitectónico Avanzado por la Columbia University de Nueva York, donde recibió el GSAPP Honor Award for Excellence in Design. Actualmente es doctorando de la UPC en Barcelona. Después de la experiencia profesional en los estudios de Alison + Peter Smithson y Enric Miralles, fundó A i B estudi d'arquitectes, un estudio dedicado a la práctica crítica de la arquitectura contemporánea.

www.aib.cat

\footnotetext{
19 "Si el mapa se opone al calco es precisamente porque está totalmente orientado hacia una experimentación que actúa sobre lo real. El mapa no reproduce un inconsciente sobre sí mismo, lo construye. (...) El mapa es abierto, capaz de ser conectado en todas sus dimensiones, desmontable, alterable, susceptible de recibir constantemente modificaciones. Puede ser roto, alterado, adaptarse a distintos montajes, iniciando por un individuo, un grupo, una formación social. Puede dibujarse en una pared, concebirse como una obra de arte, construirse como una acción política o como una meditación.

Una de las caracteristicas más importantes del rizoma, quizá sea la de tener siempre múltiples entradas; (...) Contrariamente al calco, que siempre vuelve 'a lo mismo', un mapa tiene múltiples entradas. Un mapa es un asunto de 'performance', mientras que el calco siempre remite a una supuesta "competance'."

Deleuze, Gilles / Félix Guattari; "Rhizome", Mille Plateaux. Capitalisme et schizophrénie, Minuit, Paris, 1980

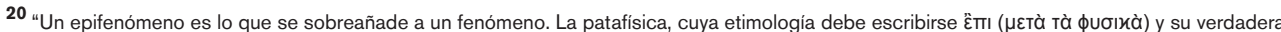
ortografia 'patafísica, precedida de un apóstrofe, para evitar un fácil retruécano, es la ciencia de lo que se sobreañade a la metafísica, sea en sí misma, sea fuera de ella, extendiéndose tan lejos de la metafísica como ésta se extiende más allá de la física. (...) La patafísica será la ciencia de lo particular, aunque se diga que no hay ciencia más que de lo general. Estudiará las leyes que rigen las excepciones; explicará aquel universo suplementario al nuestro, o menos ambiciosamente, describirá un universo que se puede ver, y que quizá se deba ver, en lugar del tradicional; dará cuenta de las leyes que se creyó descubrir en ese Universo como correlaciones a su vez de excepciones, aunque más frecuentes, en todos aquellos casos de hechos accidentales que, al reducirse a excepciones poco excepcionales, no tienen la atracción de la singularidad. DEFINICIÓN: La patafísica es la ciencia de las soluciones imaginarias, que atribuye simbólicamente a los lineamentos las propiedades de los objetos descritos por su virtualidad."

Jarry, Alfred; "Gestes et opinions du docteur Faustroll" (1898), Oeuvres complètes, Vol I, Gallimard, París, 1972, pág 668-669.

21 Jarry, 1898, pág 658
} 